\title{
Negative Gravitaxis in Overwintering Halyomorpha halys (Hemiptera: Pentatomidae) ${ }^{1}$
}

\author{
Benjamin D. Chambers, ${ }^{2,5}$ Thomas P. Kuhar, ${ }^{3}$ Tracy C. Leskey, ${ }^{4}$ \\ Georg Reichard, ${ }^{2}$ and Annie R. Pearce ${ }^{2}$ \\ J. Agric. Urban Entomol. 36: 109-114 (2020)
}

KEY WORDS Structural nuisance pest, brown marmorated stink bug, diapause, home invasion, geotaxis

The brown marmorated stink bug, Halyomorpha halys (Stål) (Hemiptera: Pentatomidae), is a significant household and agricultural pest (Leskey \& Nielsen 2018). Each fall, adult $H$. halys seek overwintering sites in houses and other buildings. Tens of thousands may infest a single home (Inkley 2012). Pest control options against shelter-seeking $H$. halys may include traps and pesticide applications on building exteriors (Watanabe et al. 1994b), and insecticide-treated window screens that can both exclude and kill (Mooneyham et al. 2016). These control methods may require exterior access to upper story features because overwintering $H$. halys are found at various heights above ground level. Watanabe et al. (1994b) found higher capture rates in traps leaning against the wall at ground level than in those under eaves and on roofs. Cambridge et al. (2015) surveyed two four-story college dormitories over a single winter and found significantly more $H$. halys inside the building on the fourth floor than on the first floor. Lee et al. (2014) found more $H$. halys in tree cavities than in fallen logs or leaf litter. It is unclear why some structures had more bugs high above ground and others close to the ground, but site characteristics such as vegetation and structural features may be relevant. For example, Bergh \& Quinn (2018) found higher densities on dark panels and door frames, and Watanabe et al. (1994a) suggested that bugs preferred settling in brown or white traps to black ones. Movement patterns can indicate information such as common angles of approach, and what environmental or visual cues $H$. halys could be exposed to as they search for entry points. By better understanding movement patterns of shelter-seeking $H$. halys, control methods can be applied or oriented in more targeted ways.

\footnotetext{
${ }^{1}$ Accepted for publication 29 July 2020.

${ }^{2}$ Department of Building Construction, Bishop Favrao Hall, Room 330A, Virginia Tech, 1345 Perry St., Blacksburg, VA 24061.

${ }^{3}$ Department of Entomology, Price Hall, Room 216A, Virginia Tech, 170 Drillfield Drive, Blacksburg, VA 24061.

${ }^{4}$ U.S. Department of Agriculture, Appalachian Fruit Research Station, 2217 Wiltshire Road, Kearneysville, WV 25430.

${ }^{5}$ Corresponding author, E-mail: bdc0112@vt.edu
} 


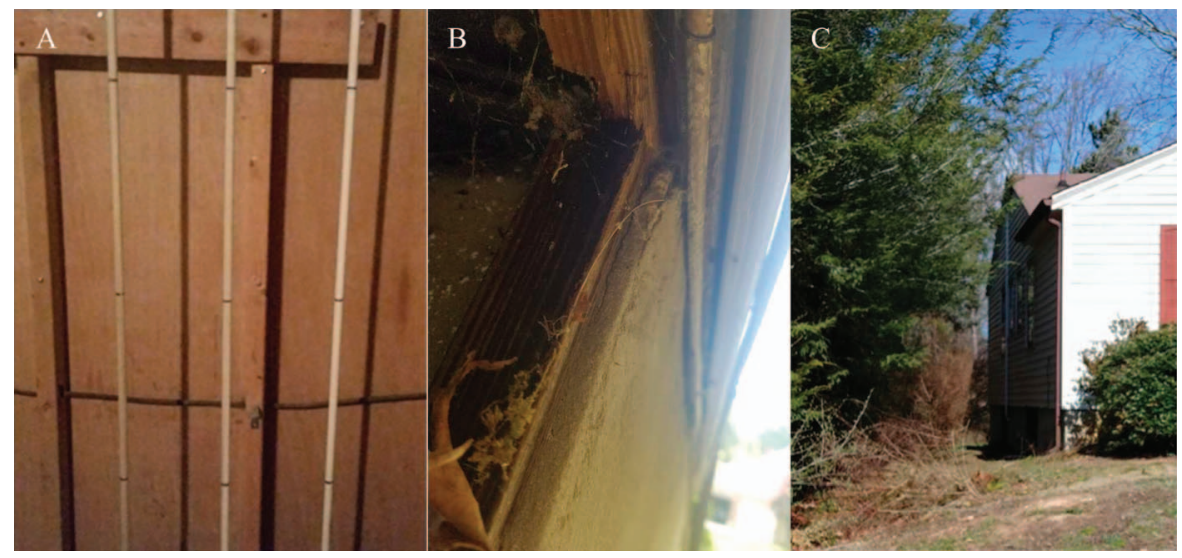

Fig. 1. (A) Vertically suspended dowels for gravitaxis laboratory experiments on $H$. halys adults. (B) The opening under the cladding at the joint between it and the masonry, at the corner of a basement window. (C) The high activity side of the house with adjacent trees.

Gravitaxis, sometimes called geotaxis in older literature (Beckingham et al. 2005), is movement response to gravitational force, and a possible cue in shelterseeking patterns. Gravitaxis has been observed in non-shelter-seeking $H$. halys. Second instars exhibited strong negative gravitaxis (i.e., moving upward), and, therefore, nymph traps opening towards the ground were more effective (AcebesDoria et al. 2016). Similarly, feeding adults appeared to cause the most damage to fruits in the upper canopy in border rows, but the least damage in the lower canopy in the interior of an orchard block (Joseph et al. 2013).

We performed controlled laboratory tests of gravitaxis to characterize the role of gravitaxis in the movement patterns of $H$. halys seeking entry to buildings for winter shelter. Laboratory observations were supported by an observational study conducted on several buildings in Blacksburg, VA.

Adult $H$. halys used in the laboratory experiments were collected from overwintering structures in the fall and winter of 2015 by gently brushing them into a scoop, then putting them into 19-L buckets (with holes drilled in the sides for ventilation) containing paper and foam insulation pieces. The overwintering bugs were kept in the buckets in darkness at $10^{\circ} \mathrm{C}$ until the time of the experiment. Immediately before the experiment, sufficient bugs of each sex for all repetitions were removed from storage and placed in a mesh holding cage $(35 \mathrm{~cm}$ in height, width and length) at $15^{\circ} \mathrm{C}$. Disturbance and elevated temperature were sufficient to rouse the bugs into movement and shelter-seeking. No bug was reused in the experiments.

Laboratory experiments were performed in a dark room maintained at $15^{\circ} \mathrm{C}$ to simulate conditions $H$. halys might experience after locating a site for overwintering. A dim red light allowed observations by researchers. Apparatus used to quantify movement was based on that by Acebes-Doria et al. (2016). Three wooden dowels (each $914 \mathrm{~mm}$ long and $13 \mathrm{~mm}$ in diameter) were vertically suspended from a shelf using twine (Figure 1A). Each dowel was marked at a center release point 
and at response points $315 \mathrm{~mm}$ above and below the release point. For each trial, an $H$. halys was removed from the holding cage and placed onto a strip of paper. The paper was held perpendicular to the release point until the bug moved onto the dowel, typically within a few seconds. This perpendicular positioning forced bugs to face horizontally rather than vertically when they were released onto the dowel. Once a bug crossed a response point, the response was recorded and the bug was removed. All bugs completed the test with a definitive response in $<5$ min. After each trial, the dowel was wiped down with a damp cloth and allowed to dry before reuse. A total of 30 bugs were tested, with equal numbers of males and females. Chi-squared tests were performed using an expected even distribution of up and down movement (i.e., 50\% each) (JMP Pro 13; SAS Institute 2016).

In the laboratory experiment, $25 \mathrm{H}$. halys (83\%) moved upward and the rest (17\%) moved downward ( $\left.\chi^{2}=14.555, \mathrm{df}=1, P=0.0001\right)$, providing evidence that $H$. halys exhibits negative gravitaxis during winter shelter seeking. No difference between sexes was found for direction moved $\left(\chi^{2}=2.288\right.$, $\left.\mathrm{df}=1, P=0.1304\right)$. These results are similar to the nymphal geotaxis experiments using the same apparatus by Acebes-Doria et al. (2016), which saw 100\% upward movement.

Potential field observation sites in southwestern Virginia were initially selected based on prior knowledge and convenience for sampling, as well as participation solicited through a neighborhood listserv. The houses participating in the neighborhood listserv anecdotally had high activity and abutted a community garden in which gardeners complained of $H$. halys pest pressure. The participation call asked for a reply if the home occupants had noticed many bugs and were willing to allow researchers access. Each volunteer home was checked at least once. Because shelter-seeking behavior occurs only for a short period of time, sites were not revisited if few $(\mathrm{n}<10)$ or no $H$. halys were observed.

Over 20 structures were visited and movement measurements were taken at 10 sites; however, only two structures had sufficiently high counts to be used for comparison with the laboratory results. One site was a single-story home in a neighborhood, and the other was a five-story academic building on the campus of Virginia Tech, Blacksburg, VA. The structure and local environment of each building exterior was different, including vegetation, sun exposure, and material. While these field results were limited, we believe they illustrated the laboratory results, and resulted in some relevant observations made during the visits.

The two structures were visited between 14:00 and 17:00 h on multiple nonrainy days in September and October 2015, the time when the highest overwintering site searching activity was expected (Bergh \& Quinn 2018). At each site, a researcher visually surveyed an exterior wall, starting from the top left corner, and moving back and forth until the entire wall had been examined. The direction toward which each $H$. halys was moving in the vertical plane (the wall) were recorded as a tally on a compass grid on the data sheet (Figure 2). Directional bins were given letter signifiers, A-H, clockwise starting from up-left. Researchers visually estimated in which of the eight 45-degree arcs each bug was moving, and marked the appropriate tally box. Only bugs on vertical planes were considered. Bugs were ignored if they were within approximately $10 \mathrm{~cm}$ of a geometrical discontinuity that would significantly impede movement in any direction, such as the underside of a window sill. No individual was counted twice, and scans were limited to $5 \mathrm{~min}$ to prevent accidental double counting. Observations from the two buildings were pooled. Chi-squared tests were performed on the pooled data using 


\begin{tabular}{|c|c|c|c|c|c|}
\hline $\boldsymbol{\wedge A}$ & $11 \%$ & $\uparrow \mathbf{B}$ & $42 \%$ & $\mathrm{C} \nearrow$ & $13 \%$ \\
\hline$\leftarrow \mathbf{H}$ & $9 \%$ & \multicolumn{2}{|c|}{ 仓 $\mathbf{U p}$ 介 } & $\mathbf{D} \rightarrow$ & $12 \%$ \\
\hline$\swarrow \mathbf{G}$ & $3 \%$ & $\downarrow F$ & $7 \%$ & $E \searrow$ & $3 \%$ \\
\hline
\end{tabular}

Fig. 2. Vertical plane compass for $H$. halys movement data collection divided into $45^{\circ}$ arcs, with percentages of initial movement directions ( $n=202$ observations) of adult $H$. halys that flew onto sides of the two highest activity buildings in Blacksburg, VA, during September and October 2015.

an expected value of $12.5 \%$ for each of the eight direction bins in the vertical plane, as would be expected if $H$. halys has no directional preference. To evaluate only the vertical component of movement on the buildings, an expected value of $50 \%$ was used for up and down movement.

A total of $202 \mathrm{H}$. halys were observed over 15 sessions on the two buildings. More direct upward movement was observed than sideways movement, and more sideways movement was observed than downward. When evaluating all eight directional bins, there was a significant difference in movement directions $\left(\chi^{2}=\right.$ 136.1086, $\mathrm{df}=7, P<0.0001)$. Of these observations, $66 \%$ were upwards or up and to the side (Bins A, B, C) and only $13 \%$ were downwards or down and to the side (Bins E, F, G). Analysis of 158 records with a vertical component (Bins A, B, C, E, $\mathrm{F}, \mathrm{G})$ indicates a preference for upward movement $\left(84 \% ; \chi^{2}=81.0311 \mathrm{df}=1\right.$, $P<0.0001$ ). While these observations were limited to two structures, they support the laboratory results, and resulted in some secondary observations of interest.

Acebes-Doria et al. (2016) demonstrated that $H$. halys nymphs tend to drop rather than walk downward. We did not collect data on dropping behaviors. However, in the field observation study, we observed very few bugs dropping from the structures unless they were disturbed during specimen collection after counts had been made.

Movement patterns may be influenced by the direction in which $H$. halys are facing when they first arrive at a building. In our field observations, bugs were observed walking from the ground onto the sides of buildings, and, therefore, many would have been facing upwards from the start. Additionally, $H$. halys in flight anecdotally tend to have their abdomens hanging down below their heads, possibly as a result of weight distribution and body structure. When alighting on a vertical plane, this may result in the bugs initially facing upwards. Future research should explore patterns in initial directions faced and their influence on movement patterns.

Various trap configurations for $H$. halys walking up and down trees have been tested (Acebes-Doria et al. 2016), and for H. halys walking on the exterior of buildings searching for winter harborage (Watanabe et al. 1994b). If movement is primarily upwards, as our results suggest, then it follows that downward-facing trap entrances may be more effective, and that obstructions limiting upward movement 
towards those traps could potentially reduce their efficacy. On the other hand, obstructions could possibly be used to guide $H$. halys away from untreated openings, towards traps, or even away from structures entirely.

Our observations on buildings were taken in the late afternoon, which is the time of highest activity on structural exteriors (Bergh \& Quinn 2018). Initially, we attempted to take data at other earlier times in the day but did not observe any $H$. halys. We note that virtually all the activity we recorded was on southwestfacing walls, which is in contrast to other findings indicating that most activity tends to be on the north and east sides (Bergh \& Quinn 2018, Hancock et al. 2019), which would tend to be cooler in the Northern Hemisphere. We note that in both structures, the high-activity side was shaded by trees. Watanabe et al. (1994a) showed that $H$. halys may leave shelters again during the settling period and speculated that the effects of time and temperature could be relevant to that behavior. Future research should determine the specific time or temperature ranges during which $H$. halys enter or exit.

We noted that at the structure and side where most observations were taken, more $H$. halys appeared to be walking onto the building from the ground than were flying to it. This was on a side of the house where a hedgerow of evergreen trees was planted approximately $2 \mathrm{~m}$ from the building, with branches extending to within $1 \mathrm{~m}$ (Figure 1B). The bottom $0.75 \mathrm{~m}$ of the wall was concrete masonry, with a thin concrete veneer (Figure 1C). While no data on the initial locations of the individual insects on the wall were recorded, the relative number of bugs walking onto the bottom portion from the ground appeared to be high. As H. halys are moving upwards on a building, the starting point on the wall may determine the access point. Individuals alighting higher on a wall may be more likely to reach elements in the walls and eaves, such as soffit vents, due to the shorter distance from landing points than from the ground. Meanwhile, those walking up onto a building from the ground may encounter overhangs and openings where cladding begins. In the case of this house (Figure 1B, C), that overhang included an opening to the cavity between the cladding and sheathing, which many individuals were observed entering. This could explain the results of the experiment by Watanabe et al. (1994b) that found more bugs in trap shelters on the ground than under eaves on their two-story building. Therefore, we suggest future research should investigate how $H$. halys approaches and moves onto buildings, including comparisons between the proximity, height, and type of vegetation. We also note that in sufficient numbers, overwintering $H$. halys could possibly interfere with the design function of ventilated wall cavities between sheathing and cladding. Our observations of adults entering such a cavity suggests future research into the prevalence and impact of the use of ventilated cavities as winter refugia.

\section{Acknowledgments}

We thank those who allowed us to observe bug movements on the sides of their buildings, and the students of the Virginia Tech VIPR Lab for assistance in counting and collecting insects. This research was supported in part by USDA-NIFA SCRI awards \#2011-5118130937 and \#2016-51181-25409, the Virginia Tech BioBuild program, and the Virginia Pest Management Association. 


\section{References Cited}

Acebes-Doria, A. L., T. C. Leskey \& J. C. Bergh. 2016. Development and comparison of trunk traps to monitor movement of Halyomorpha halys nymphs on host trees. Entomol. Exp. Appl. 158: 44-53.

Beckingham, K. M., M. J. Texada, D. A. Baker, R. Munjaal \& J. D. Armstrong. 2005. Genetics of graviperception in animals. Adv. Genet. 55: 105-145.

Bergh, J. \& N. Quinn. 2018. Can the dispersal behavior of Halyomorpha halys (Hemiptera: Pentatomidae) inform the use of insecticide-treated netting to mitigate homeowner issues from its fall invasion? Environ. Entomol. 47: 1501-1508.

Cambridge, J., A. Payenski \& G. C. Hamilton. 2015. The distribution of overwintering brown marmorated stink bugs (Hemiptera: Pentatomidae) in college dormitories. Fla. Entomol. 98: 1257-1259.

Hancock, T. J., J. Bergh, D.-H. Lee, W. Morrison \& T. Leskey. 2019. Presence of the invasive brown marmorated stink bug Halyomorpha halys (Stål) (Hemiptera: Pentatomidae) on home exteriors during the autumn dispersal period: results generated by citizen scientists. Agric. For. Entomol. 21: 99-108.

Inkley, D. B. 2012. Characteristics of home invasion by the brown marmorated stink bug (Hemiptera: Pentatomidae). J. Entomol. Sci. 47: 125-130.

Joseph, S. V, J. C. Bergh, S. E. Wright \& T. C. Leskey. 2013. Factors affecting captures of brown marmorated stink bug, Halyomorpha halys (Hemiptera: Pentatomidae), in baited pyramid traps. J. Entomol. Sci. 48: 43-51.

Lee, D.-H., J. P. Cullum, J. L. Anderson, J. L. Daugherty, L. M. Beckett \& T. C. Leskey. 2014. Characterization of overwintering sites of the invasive brown marmorated stink bug in natural landscapes using human surveyors and detector canines. PLoS One. 9: e91575.

Leskey, T. C. \& A. L. Nielsen. 2018. Impact of the invasive brown marmorated stink bug in North America and Europe: history, biology, ecology, and management. Annu. Rev. Entomol. 63: 599-618.

Mooneyham, K. L., J. D. Aigner \& T. P. Kuhar. 2016. Control of brown marmorated stink bug with insecticide-treated window screens, 2015. Arthropod Manag. Tests 41: tsw021.

SAS Institute. 2016. JMP Pro version 13.0.0. SAS Institute, Cary, NC.

Watanabe, M., R. Arakawa, Y. Shinagawa \& T. Okazawa. 1994a. Fluctuation in brown marmorated stinkbug's winter migrations into human dwellings. Japan Soc. Med. Entomol. Zool. Anim. Heal. 45: 25-31.

Watanabe, M., R. Arakawa, Y. Shinakawa \& T. Okazawa. 1994b. Methods for preventing brown marmorated stink bug infestation. Japan Soc. Med. Entomol. Zool. Anim. Heal. 45: $311-317$. 